\title{
Modeling Effects of Floating Curtain Weirs and Controlling Algal Blooms in a Subtropical Reservoir of China
}

\author{
Ranojit Kumar Dutta ${ }^{1,2,3, *}$, Jun Ma ${ }^{1,4}$, Baishakhi Das ${ }^{5}$, Defu Liu ${ }^{1,4}$ \\ ${ }^{1}$ College of Hydraulic \& Environmental Engineering, China Three Gorges University, Yichang, 443002, Hubei, China \\ ${ }^{2}$ Faculty of Science and Engineering, City University, Dhaka 1216, Bangladesh \\ ${ }^{3}$ Faculty of Engineering, Bangladesh University of Engineering and Technology (BUET), Dhaka-1000, Bangladesh \\ ${ }^{4}$ Hubei Key Laboratory of Ecological Restoration of River-lakes and Algal Utilization, \\ Hubei University of Technology, Wuhan 430068, China \\ ${ }^{5}$ International Relations, Department of Political Science, NU, Bangladesh \\ *Corresponding author: ranojit.dutta83@gmail.com
}

Received March 04, 2019; Revised April 24, 2019; Accepted May 23, 2019

\begin{abstract}
Algal blooms occur frequently in Xiangxi Bay (XXB), which is one of the largest tributaries of the Three Gorges Reservoir (TGR). Floating curtain weirs (FCWs) are hydraulic structures that act as a barrier to divert density currents and diffuse heat across the width of the water body. Numerical modeling of FCWs is become a widely accepted method for controlling algal blooms. A laterally averaged two-dimensional hydrodynamic and water quality model (CE-QUAL-W2) was used to simulate the effects of FCWs, including those on water temperature, hydrodynamics and chlorophyll-a concentrations, for XXB. The developed model was calibrated using data collected in XXB from January to December 2010. The results indicated that the maximum chlorophyll-a concentrations observed were $74-154 \mathrm{mg} / \mathrm{m}^{3}$ at the XX09, XX06 and XX01 sampling sites. The performance of the FCWs suggests that the overall chlorophyll-a concentrations are markedly reduced by more than $85 \%$ as a function of the FCW heights and locations. Seasonally, an algal bloom reduction rate of more than $62 \%$ was observed in the summer. FCWs with heights of 3, 5, and $7 \mathrm{~m}$ reduced algal blooms by up to 99\% at XX09 during March 26-28, April 24-27, July 18-26, August 5-20, and 23-28, and September 3-8 and 12-16, respectively. Therefore, the proposed FCWs can reduce algal blooms and improve water quality to save domestic water and aquatic ecosystems in XXB.
\end{abstract}

Keywords: Modeling effects, Floating curtain weirs (FCWs), Xiangxi Bay (XXB), Algal blooms, CE-QUAL-W2 model, Three Gorges Reservoir (TGR)

Cite This Article: Ranojit Kumar Dutta, Jun Ma, Baishakhi Das, and Defu Liu, "Modeling Effects of Floating Curtain Weirs and Controlling Algal Blooms in a Subtropical Reservoir of China." American Journal of Water Resources, vol. 7, no. 2 (2019): 42-49. doi: 10.12691/ajwr-7-2-1.

\section{Introduction}

Algal blooms occur seasonally in XXB of the Three Gorges Reservoir (TGR). Geographically, the TGR is located in a subtropical monsoon climate region where the summer is warmer and wet and the winter is cooler and dry [1]. Algal bloom occur frequency in spring (March, April and May), summer (June, July and August) and autumn (September, October and November) [1,2]. Experts assume that density currents are the main environmental issue influencing algal blooms year round in XXB of the TGR [1,3,4]. Moreover, density currents transport nutrients, solid and silts [1,5-9]. Long-term data show that more severe algal blooms occur at midstream than upstream and downstream in XXB $[1,4,10]$. Density currents are also affected by the upstream inflow and separate into two paths over the surface as overflows (warm water float) and under the bottom as an underflow (cold water underneath) in XXB [11]. Simultaneously, density currents intrude into XXB from the mainstream of the Yangtze River (YR) through the surface, middle and bottom as overflows, interflows and underflows [1,4]. In summer, the cold inflow submerges to the bottom as an underflow, which creates differences in the density between the surface and bottom. At the same time, the middle layer densities of XXB are equal to the mainstream ambient water densities. Thus, large amounts of density currents intrude in XXB along the surface and middle flows [1,12]. The upstream inflow and downstream intrusive density current interact at midstream to cause severe algal blooms at midstream.

Notably, numerous investigations of algal blooms have been conducted for XXB, but previous studies have not discussed the exact causes and how to control them and 
the occurrence of density currents. Due to the deficiency of research concerning the control of algal blooms, we discovered a novel technique the floating curtain weir method to divert density currents and control algal blooms in XXB. Floating curtain weirs (FCWs) have been used to control algal blooms in XXB through a laterally averaged two-dimensional hydrodynamic and water quality model (CE-QUAL-W2). Previous studies used FCWs to control algal blooms in different reservoirs [13-16]. Curtain weirs effectively controlled algal blooms in Terauchi Dam Reservoir [17]. FCWs affect the flow by preventing horizontal passage of water, which is forced to travel underneath [18]. The submergence level of the interflow should change due to the effect of curtain weirs [19]. The chlorophyll-a concentrations changes with the FCW height because of variation in the submergence level of the interflow. Compared with conventional algal bloom control methods, FCW numerical models are a much more attractive, much less expensive and time-saving algal bloom control technique.

The objective of this study is to control algal blooms in XXB of the TGR via application of FCWs using a two-dimensional, laterally averaged, hydrodynamic model based on CE-QUAL-W2. We focus on the effects of FCWs on the hydrodynamics, thermal structure and chlorophyll-a concentrations in XXB of the TGR. The performance of the FCWs was evaluated based on the reduction in chlorophyll-a predicted by the model, which was termed the weir efficiency.

\section{Materials and Methods}

\subsection{Study Area}

$\mathrm{XXB}$ is located from $110^{\circ} 25^{\prime} \mathrm{E}$ to $111^{\circ} 06^{\prime \prime} \mathrm{E}$ and from $30^{\circ} 57^{\prime} \mathrm{N}$ to $31^{\circ} 34^{\prime} \mathrm{N}$ at the lower reach of the TGR and middle reach of the YR in Hubei Province, China. XXB is one of the largest tributaries of the TGR. Due to its connection with the mainstream YR of the TGR, a large amount of density currents intrude into XXB at different levels, such as the surface, middle and bottom with water level daily fluctuations (WLDFs) $[1,3,4]$. The XXB CE-QUAL-W2 model is represented by 64 longitudinal segments, each $500 \mathrm{~m}$ in length, and 109 vertical layers, each $1 \mathrm{~m}$ thick [1], as shown in Figure 1(b).

\subsection{Incorporation of FCWs into the CE-QUAL-W2 Model for XXB}

The CE-QUAL-W2 is a 2D hydrodynamic and water quality model $[20,21,22]$. The FCWs are set at specified cell locations, such as the segment [I] and layer number [K], [i.e., cell (K, I)], as shown in Figure 1(b). The FCWs are always located in the reservoir water surface during the simulation period (Figure 1(c)). All meteorological data were obtained from a hydrological station at Xingshan, as shown in Figure 1(a) and the China Three Gorges Corporation (CTGC) for the year 2010 [1].

\subsection{FCWs Mechanism}

FCWs were installed at three different sites (XX09, XX06 and XX01) of XXB with heights of $3 \mathrm{~m}, 5 \mathrm{~m}$ and $7 \mathrm{~m}$, respectively, as shown in Figure 1(c). FCWs effectively act as a barrier to the flow and diffusion of heat across the width of the water body. The inflow forms a plunge flow before the FCWs and later travels as an interflow under the curtain weir (Figure 1 (c)). Meanwhile, the mixing depth exceeds the critical depth according to the critical depth theory due to the effect of the FCWs [23]. When the inflow or intrusive flow passes under the FCW as an interflow, mutual forces are exerted between the interflow and FCW [24,25]. The interflow exerts forces on the curtain weirs, and simultaneously the FCWs must exert an equal and opposite force on the interflow or ambient water as a result, eddies are formed that produce heat and affect the thermal structure at XXB. FCWs lead to enhanced mixing in the interior of the water body, resulting in formation of an oscillation in the boundary layer. The XXB metalimnion layer is very thin, due to the effect of the FCWs on algal bloom intrusion propagated from the epilimnion to the hypolimnion by boundary mixing $[1,26]$.
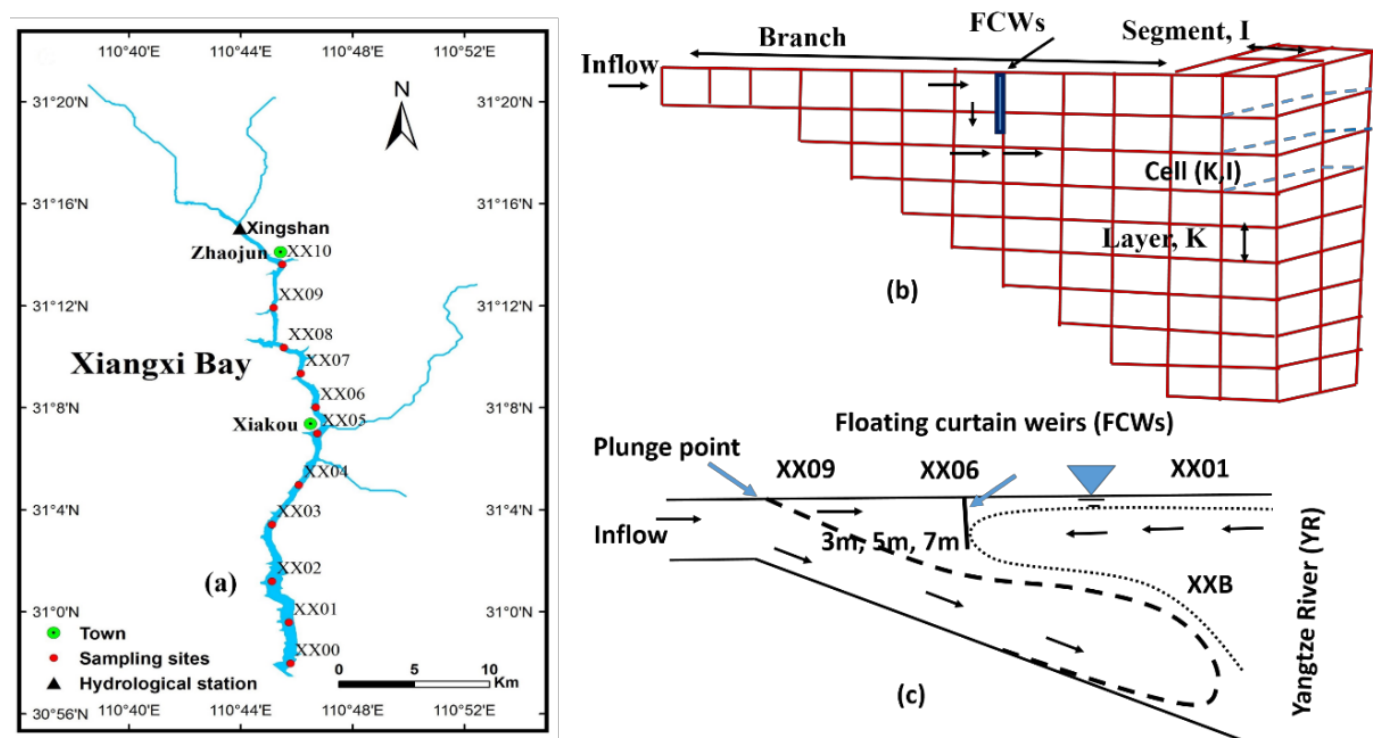

Figure 1. (a) Location of the sampling sites in XXB, (b) Schematic representations of the curtain weirs and (c) Floating curtain weir (FCWs) in XXB 




Figure 2. Spatial effects of the FCWs on hydrodynamics at XXB

\section{Results}

\subsection{The Effects of FCWs Effect on Hydrodynamics in XXB of the TGR}

FCWs have significantly effects on density currents in $\mathrm{XXB}$ of the TGR. The density currents in XXB are influenced by the upstream inflow and intrusive flows from the mainstream of the TGR. After installation of the FCWs, the velocity changed significantly in the XXB, as shown in the Figure 2. The velocities were increased due to the effects of the FCWs at XX09 but decreased at XX06 and XX01 on June 20, 2010. In March, the velocities at all three locations without FCWs increased because of release of water from the TGR. In April, May, June and July the velocities at all three segments without curtain weirs decreased because of the flood control level of $145 \mathrm{~m}$ of the TGR at the same time, surface intrusion flowed from downstream to upstream, but the FCWs diverted all of the density currents. In the summer season, the cold inflow submerged the upstream flow and propagated to the downstream flow as an underflow. In July, the velocity increased without the curtain weir because of high inflow from upstream to downstream however, the velocity was decreased at all three segments due to the effect of the FCWs, because most of the inflow was barricaded by the FCWs. The proposed FCWs directly influenced the hydrodynamics, such as the water velocity and temperature, and vertical mixing, which subsequently reduced algal blooms in XXB of the TGR.

\subsection{Temporal Effects of the FCWs on Temperature}

The temporal effects of FCWs on temperature in XXB are illustrated in Figure 3. Figure 3 shows temperature difference (TDf) range from $-0.5^{\circ} \mathrm{C}$ to $0.5^{\circ} \mathrm{C}$ for the case with on FCWs and with FCWs during the whole simulation period in 2010. The temperature decreased for more than 297 days due to the effect of FCWs at XX09. The temperature maximum decreased by $9^{\circ} \mathrm{C}$ at XX09 on July 23, 2010 (Julian Day 204.401). In winter and spring, the temperature decreased by an average of $2^{\circ} \mathrm{C}$ for 88 days and $1.7^{\circ} \mathrm{C}$ for 36 days due to application of the $7 \mathrm{~m}$ FCWs at XX09. In summer and autumn, the temperature decreased by an average of $5.58^{\circ} \mathrm{C}$ for 81 days and $5.14^{\circ} \mathrm{C}$ for 91 days, respectively at XX09, as shown in Figure 3. The temperature increased for more than 70 days due to the effect of FCWs at XX09, and the maximum temperature increased up to $3^{\circ} \mathrm{C}$ on April 13 (Julian Day 103.401). The temperature increased by an average of $0.77^{\circ} \mathrm{C}$ for 56 days and $0.13^{\circ} \mathrm{C}$ for 12 days in spring and summer, respectively, by $0.16^{\circ} \mathrm{C}$ in winter at upstream of $\mathrm{XXB}$. In winter, the temperature was increased observed on January 5 and 10 and, February 9-11, 20, 23-24 and 28 for the $3 \mathrm{~m}, 5 \mathrm{~m}$ and $7 \mathrm{~m}$ FCWs at XX09. In spring, the temperature increased on March 1-20 and, 22-24, April 1, 6-8, 11-15 and 19-25 and May 5-6, 19-22 and 25 for the 3 m FCWs, on March 1-9, 11-27 and 31, April 1-2, 6-16 and 19-26 and May 5-6 for the $5 \mathrm{~m}$ FCWs and on March 1-11 and 13-31, April 1-3 and 6-26 and May 5-6 for the $7 \mathrm{~m}$ FCWs at XX09 (Figure 3). In summer, an increased temperature observed on June 6-16 and 17-19 for the $3 \mathrm{~m}$, 
$5 \mathrm{~m}$ and $7 \mathrm{~m}$ FCWs at XX09. In winter, a temperature decrease observation on January 1-4, 6-9, 11-23 and 25-31 and, February 1-8, 12-19, 21-22 and 25-27 for the $3 \mathrm{~m}$ FCWs and on January 1-31, and February 1-27 for the $5 \mathrm{~m}$ and $7 \mathrm{~m}$ FCWs at XX09 (Figure 3). In spring, a temperature decrease was observed on March 25-31, April 2-5, 9-10, 16-18, and 26-30, and May 1-4, 8-18, 23-27 and 26-31 for the $3 \mathrm{~m}$ FCWs, on March 10 and 28-30, April 3-5, 17-18 and 27-30 and May 1-4, 7-31 for the $5 \mathrm{~m}$ FCWs and on March 12, April 4-5 and, 27-30, and May 1-4, 7-31 for the $7 \mathrm{~m} \mathrm{FCWs}$ at XX09 (Figure 3). In summer, a temperature decrease was observed on June 1-5 and 17-30 and August 1-31 for the $3 \mathrm{~m}, 5 \mathrm{~m}$ and $7 \mathrm{~m}$ FCWs at XX09. Temperature decreases were observed throughout autumn from September 1 to November 30 for the $3 \mathrm{~m}, 5 \mathrm{~m}$ and 7 $\mathrm{m}$ FCWs at XX09. The temperature was increased more than 345 days by application of the 7m FCWs at XX01 and decreased only 20 days. The maximum temperature increase was $4.22^{\circ} \mathrm{C}$ on August 12-13 (Julian Day 224.401-225.401) by the $7 \mathrm{~m}$ FCWs at XX01 of XXB. Temperature destratification occurred due to the effect of FCWs year round. In the beginning of spring convective overturn and additional heat is induced by the FCWs: as a result, temperature stratification was established in XXB, as shown in Figure 3. Through summer, the inflow water remains cooler than the surface water, and as a result the upstream temperature is decreased due to the effect of the FCWs. Simultaneously, warm water intrudes from the mainstream of the Yangtze River into XXB along the surface as an overflow, resulting in an increase in temperature due to the FCWs performances shown in Figure 3. When the cold inflow sinks upstream of the $\mathrm{XXB}$, the curtain weir barricades all cold inflows and the upstream temperature is decreased as a result, as shown in Figure 3. The XX09 temperature difference (TDf) between no FCWs and with FCWs was higher than that of XX06 and XX01 respectively. In midstream, both density currents (from upstream and downstream) interact; as a result, the TDf between the case with no FCWs and with FCWs are expected to very similar. The vertical temperature stratification increases both above and below the interflow density currents. The upstream inflow water temperature initially is cooler, but the effects of FCWs and mixing with ambient water rapidly increase the temperature in the midstream at XX06. The downstream temperature is higher than the upstream temperature. Warm water is blocked by the different heights of the FCWs, as observed at XX01 and shown in Figure 3. At the end of summer, the intensity of the stratification decreased gradually, and the mainstream YR from the TGR water enters XXB along the surface as an overflow density currents. Hence, the FCWs induce mechanical mixing and resist the density currents at XXB of the TGR.

\subsection{The Effect of FCWs on the Chlorophyll-a Concentrations in XXB of the TGR}

A time series of simulated chlorophyll-a concentrations for the cases with no FCWs and with FCWs is shown in Figure 4. The rates of chlorophyll-a concentration reduction varied in space and time for FCWs with heights of $3 \mathrm{~m}, 5$ $\mathrm{m}$ and $7 \mathrm{~m}$, respectively. Algal bloom reductions were considered in cases with chlorophyll-a concentrations greater than $30 \%$ for the scenarios without and with FCWs, as shown in Figure 4. The chlorophyll-a concentrations difference (CDf) between the cases with no FCWs and with FCWs was higher at XX09 than at XX06 and XX01, as shown in Figure 4. A high CDf indicated that maximum performance of the FCWs. The CDf is proportional to the algal bloom reduction rate. If the CDf increases, then the algal bloom reduction rate will increase. The maximum chlorophyll-a concentrations were $74-154 \mathrm{mg} / \mathrm{m}^{3}$ according to the scenario with no FCWs at XX09, XX06 and XX01 from July 11 to August 9, 2010. Significant chlorophyll-a concentrations were found in a few meters of water all over the surface area. After installation of the FCWs, the chlorophyll-a concentrations were reduced significantly at XX09, XX06 and XX01 of XXB, as shown in Figure 4. Days with the occurrence of algal bloom observed for the cases with no FCWs in the spring (March 26-30, April 1516 and, 24-30 and, May 1-7, 10 and 29-31), summer (June 1-5, July 16-18 and, 20-26 and August 5-20 and, 23-28) and autumn (September 3-5 and, 7-8 and 12-16) with average chlorophyll-a concentrations of $41 \mathrm{mg} / \mathrm{m}^{3}, 74$ $\mathrm{mg} / \mathrm{m}^{3}$ and $41 \mathrm{mg} / \mathrm{m}^{3}$, respectively, at XX09 (Figure 4). The maximum chlorophyll-a concentrations were 58 $\mathrm{mg} / \mathrm{m}^{3}, 136 \mathrm{mg} / \mathrm{m}^{3}$ and $53 \mathrm{mg} / \mathrm{m}^{3}$ on April 16, July 22 and September 13 at XX09. The average chlorophyll-a concentrations were markedly reduced to $25 \mathrm{mg} / \mathrm{m}^{3}, 6$ $\mathrm{mg} / \mathrm{m}^{3}$ and $0.04 \mathrm{mg} / \mathrm{m}^{3}$ on those spring, summer and autumn days, respectively, due to the effect of the $3 \mathrm{~m}$ FCWs at XX09 (Figure 4). The average chlorophyll-a concentrations are markedly were markedly reduced to $8 \mathrm{mg} / \mathrm{m}^{3}, 2 \mathrm{mg} / \mathrm{m}^{3}$ and $0.4 \mathrm{mg} / \mathrm{m}^{3}$ on those spring, summer and autumn days, respectively, due to the effect of the $5 \mathrm{~m}$ FCWs, whereas for the $7 \mathrm{~m}$ FCWs the average chlorophyll-a concentrations on those days in spring, summer and autumn were reduced to $18 \mathrm{mg} / \mathrm{m}^{3}, 1 \mathrm{mg} / \mathrm{m}^{3}$ and $1 \mathrm{mg} / \mathrm{m}^{3}$ at XX09. Days with the occurrence of algal bloom were observed in the case with no FCWs in spring (March 2628, April 5 and, 15-30 and, May 1-12, and, 20-31), summer (June 1-12, 16 and 21, July 2-7 and 16-23 and August 5-8, 10, 20 and 23-25) and in autumn (September 5-8 and, 13-17), with average chlorophyll-a concentrations of $70 \mathrm{mg} / \mathrm{m}^{3}, 89 \mathrm{mg} / \mathrm{m}^{3}$ and $48 \mathrm{mg} / \mathrm{m}^{3}$, respectively, at XX06 (Figure 4). The maximum chlorophyll-a concentrations were $135 \mathrm{mg} / \mathrm{m}^{3}, 154 \mathrm{mg} / \mathrm{m}^{3}$ and $61 \mathrm{mg} / \mathrm{m}^{3}$ on May 31, June 1and September 8 at XX06. The average chlorophyll-a concentrations were markedly reduced to $48 \mathrm{mg} / \mathrm{m}^{3}, 46$ $\mathrm{mg} / \mathrm{m}^{3}$ and $18 \mathrm{mg} / \mathrm{m}^{3}$ on those spring, summer and autumn days, respectively, due to the effect of the $3 \mathrm{~m} \mathrm{FCWs} \mathrm{at}$ XX06 (Figure 4). The average chlorophyll-a concentrations were markedly reduced to $36 \mathrm{mg} / \mathrm{m}^{3}, 45 \mathrm{mg} / \mathrm{m}^{3}$ and $10 \mathrm{mg} / \mathrm{m}^{3}$ on those spring, summer and autumn days, respectively, due to the effect of the $5 \mathrm{~m}$ FCWs at XX06. The average chlorophyll-a concentrations were markedly reduced to $22 \mathrm{mg} / \mathrm{m}^{3}, 47 \mathrm{mg} / \mathrm{m}^{3}$ and $25 \mathrm{mg} / \mathrm{m}^{3}$ on those spring, summer and autumn days, respectively, due to the effect of the $7 \mathrm{~m} \mathrm{FCWs}$ at XX06. The occurrence of algal blooms was observed in the cases with no FCWs in spring (March 22-24, April 7-10, 13-14 and 22 and, May 5-6 and, 14-15), summer (June 9-10 and, 21-24, July 3-4, 6-7, 11 and, 15-18 and, August 7,10, 14-15 and 22) and autumn (September 11,15 and, 18-20) with average chlorophyll-a concentrations of $55 \mathrm{mg} / \mathrm{m}^{3}, 88 \mathrm{mg} / \mathrm{m}^{3}$ and $35 \mathrm{mg} / \mathrm{m}^{3}$, respectively, at XX01. Maximum chlorophyll-a concentrations 
of $94 \mathrm{mg} / \mathrm{m}^{3}, 125 \mathrm{mg} / \mathrm{m}^{3}$ and $35 \mathrm{mg} / \mathrm{m}^{3}$ were observed on May 5, June 10 and September 20, respectively, at XX01 (Figure 4). The average chlorophyll-a concentrations were markedly reduced to $39 \mathrm{mg} / \mathrm{m}^{3}, 77$ $\mathrm{mg} / \mathrm{m}^{3}$ and $33 \mathrm{mg} / \mathrm{m}^{3}$ on those spring, summer and autumn days, respectively, due to the effect of the $3 \mathrm{~m} \mathrm{FCWs} \mathrm{at}$ XX01. The average chlorophyll-a concentrations were markedly reduced to $28 \mathrm{mg} / \mathrm{m}^{3}$ and $28 \mathrm{mg} / \mathrm{m}^{3}$ on those spring and summer days, respectively, due to the effect of the $5 \mathrm{~m}$ FCWs at XX01. The average chlorophyll-a concentrations were markedly reduced to $22 \mathrm{mg} / \mathrm{m}^{3}$ and $30 \mathrm{mg} / \mathrm{m}^{3}$ on those spring and summer days, respectively, due to the effect of the $7 \mathrm{~m}$ FCWs at XX01 (Figure 4).


FCWs at XX09
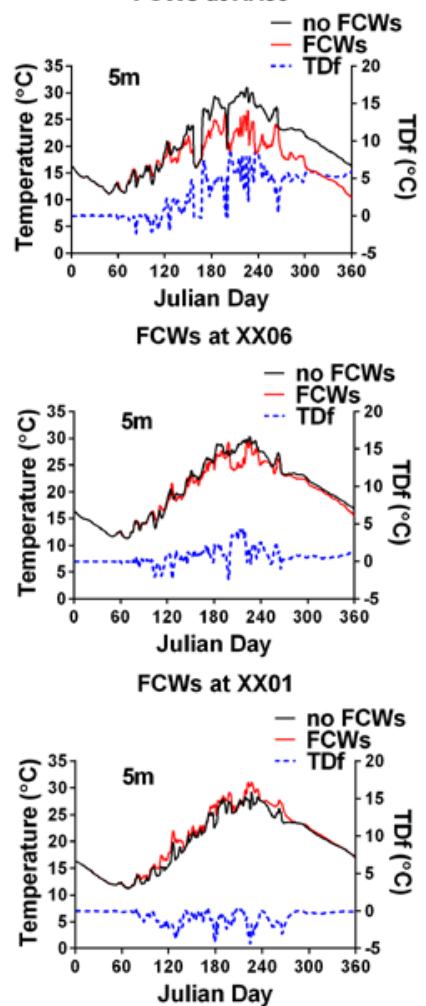
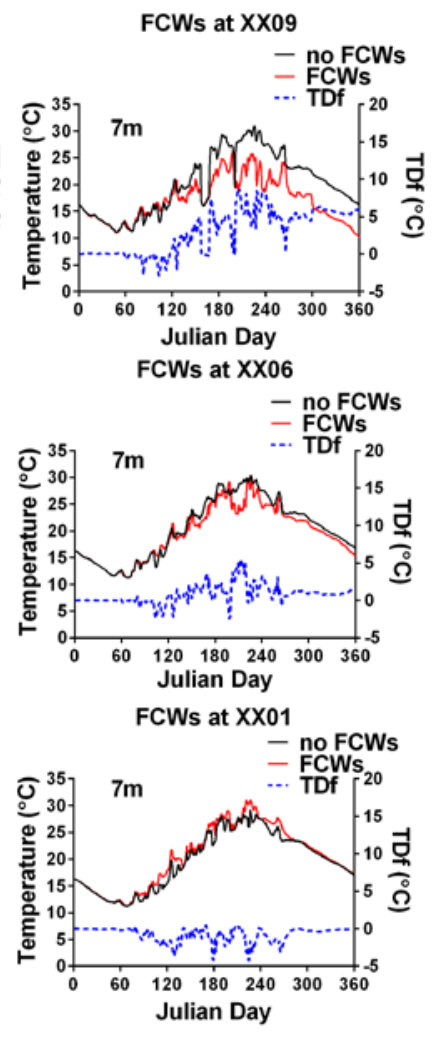

Figure 3. Temporal effects of the FCWs on the thermal structure at XXB of the TGR
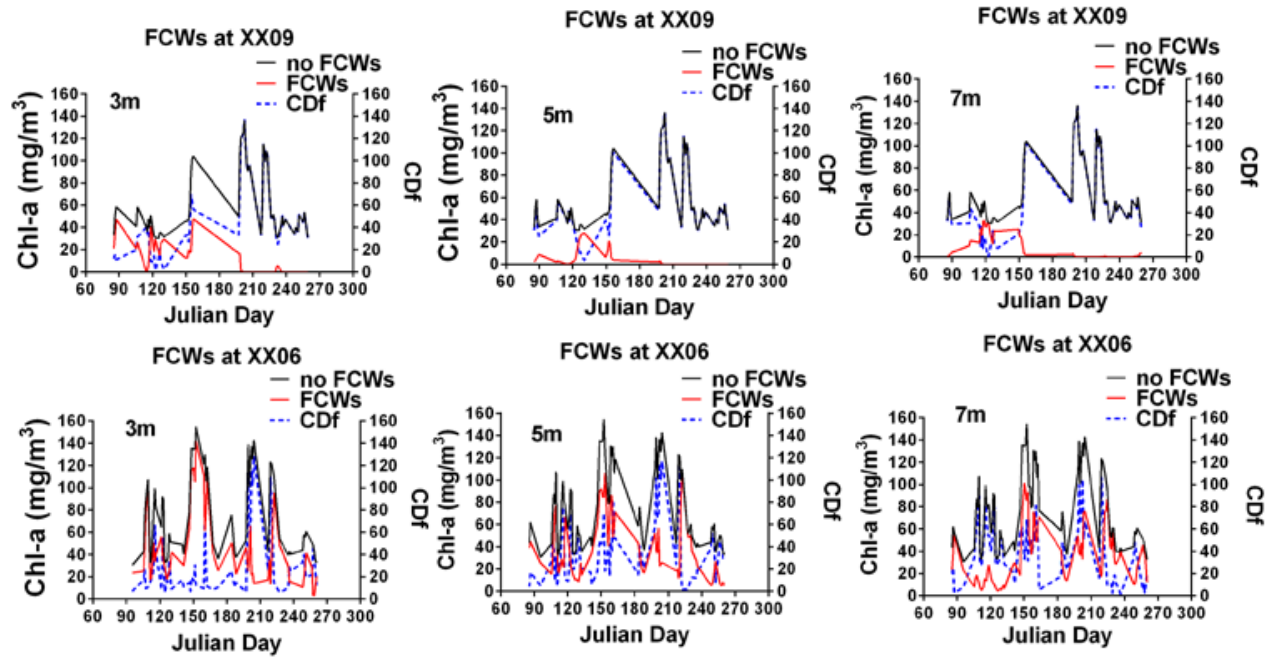

FCWs at XX01


Figure 4. Temporal effects of FCWs on Chl-a concentrations in XXB of the TGR 
Algal blooms occur underneath under the FCWs in the underflow, because most of the inflow is barricaded by the FCWs. The chlorophyll-a concentrations in the spring and summer are significantly reduced by the application of FCWs. The summer chlorophyll-a concentrations are higher at all three sites (XX09, XX06 and XX01).

\section{Effectiveness of the FCWs}

\subsection{FCW Efficiency}

The performances of the FCWs were determined using the normalized curtain efficiency $\left(F C_{e f f}\right)$, which is defined in equation (1).

$$
F C_{e f f}=\frac{F C_{\text {no } F C W s}-F C_{F C W s}}{F C_{\text {no FCWs }}} * 100 \% .
$$

The efficiency of the FCWs showed different values at different locations, such as XX09, XX06 and XX01, in XXB of the TGR (Table 1). The model also predicted an overall efficiency of the FCWs of $85 \%$, 52\% and $30 \%$ at XX09, XX06 and XX01, respectively (Table 1). The performances of the FCWs by heights were greater than $61 \%, 59 \%$ and $47 \%$ for the $5 \mathrm{~m}$, $7 \mathrm{~m}$ and $3 \mathrm{~m}$ FCWs, respectively. Seasonally, reductions in the rates of algal blooms of more than $62 \%, 54 \%$ and $50 \%$ were observed in the summer, autumn and spring in 2010 respectively (Table 1). In winter, less than $30 \%$ of the day had algal blooms, which was not occurred.

\section{Discussion}

\subsection{Effects of FCWs on Hydrodynamics in XXB of the TGR}

The proposed FCWs were simulated using a two-dimensional, laterally averaged hydrodynamic model based on CE-QUAL-W2. The CE-QUAL-W2 model is appropriate for XXB of the TGR [1]. Using FCWs through the CE-QUAL-W2 model, algal blooms were controlled in different reservoirs, such as Daecheong Dam Reservoir, Korea, Terauchi Dam Reservoir, Japan [13-17]. FCWs were installed at three different upstream, midstream and downstream corresponding to XX09, XX06 and XX01 in XXB of the TGR, respectively. When an overflow density current occurs, the FCWs should cover the epilimnetic depth and resist the overflow density current, as shown in Figure 2. An overflow density current exerts excess hydrostatic pressure, and thus these currents flow in all directions but are obstructed by the FCWs $[9,27,28]$. Overflow density currents are susceptible to interactions with FCWs and are diverted downward, as shown in Figure 2. Thermal stratification is responsible for the density differences in $\mathrm{XXB}[1,29]$. In the $\mathrm{XXB}$, the metalimnion strata is very thin, and as a result epilimnion algal bloom transportation to the hypolimnion occurs very rapidly due to the effect of FCWs. Density currents are always passing as an interflow under the FCWs, and thus mutual forces are exerted between the interflows and FCWs [14,24,25]. The interflow exerts a force on the FCWs, and simultaneously the FCWs must exert an equal and opposite force on the interflow and ambient water around the FCWs. XXB stratification occurred at the onset of the spring to autumn turnover $[1,30]$ after installation of the the FCWs. The simulation results showed that the stratification patterns changed and that destratification occurred in XXB.

\subsection{Effects of FCWs on Water Quality in XXB of the TGR}

In this study, FCW were used to control algal blooms in XXB through a laterally averaged two-dimensional hydrodynamic and water quality model based on the EC-QUAL-W2. Previous studies used FCWs to control algal blooms in different reservoirs [13-17]. The simulation results indicated that the reduction efficiency for algal blooms was increased by the FCWs located upstream, midstream and downstream corresponding to XX09, XX06 and XX01, respectively (Table 1). The CDf is proportional the algal bloom reduction rate. If the CDf increase, then the algal bloom reduction rate will increase. The maximum chlorophyll-a concentrations were found in the no FCWs scenario, whereas the chlorophyll-a concentrations were reduced significantly in the case with FCWs, as shown in Figure 4. The effectiveness of the FCWs was between $50 \%$ to $60 \%$ in the summer, autumn and spring (Table 1). During spring (March 26-28 and, April 24-27) and summer (July 18-26, August 5-20 and 23-28, and, September 3-8 and 12-16), the FCWs reduced algal blooms by up to $99 \%$. The FCWs interrupted all density currents and controlled algal blooms in XXB [16,31]. Long-term field monitoring data showed that algal blooms occurred more often in the spring, summer and autumn months in XXB [1]. Sometimes, severe algal blooms occur within a couple of days when reservoir resources are sufficient, such as in case with plenty of nutrients [12], and a, sufficient water temperature [30], solar radiations and, water age in the absence of any perturbation and disturbances (Figure 4). Intermediate disturbances of algal blooms occur more often depending on the intermediate disturbances hypothesis (IDH) [32,33]. Algal blooms rapidly increase with the euphotic depth to mixing depth ratio during the spring and summer [30,34]. Algal blooms would disappear rapidly if the ratio value was smaller, because the mixing depth would rapidly increase and exceed the euphotic depth, and the algal blooms would be mixed much deeper according to the critical depth theory [23]. The performance of the FCWs should destroy the thermal stratification and rapid increase in the mixing depth which exceeds the euphotic depth and the algal blooms underneath $[1,10,24]$. 
Table 1. FCW effectiveness scenarios at different locations of XXB simulated for 2010

\begin{tabular}{|c|c|c|c|c|c|c|c|}
\hline \multirow{2}{*}{$\begin{array}{c}\mathrm{XXB} \\
\text { locations }\end{array}$} & \multirow{2}{*}{$\begin{array}{l}\text { FCWs } \\
\text { height }\end{array}$} & \multirow{2}{*}{ Scenarios } & \multicolumn{3}{|c|}{ FCWs seasonal Chl-a reduction efficiency (\%) } & \multirow{2}{*}{$\begin{array}{l}\text { Yearly efficiency (\%) per } \\
\text { scenario }\end{array}$} & \multirow{2}{*}{$\begin{array}{c}\text { Average efficiency } \\
(\%)\end{array}$} \\
\hline & & & Spring & Summer & Autumn & & \\
\hline \multirow{4}{*}{ XX09 } & $3 \mathrm{~m}$ & Seg9 & 44 & 93 & 99 & 79 & \multirow{4}{*}{85} \\
\hline & $5 \mathrm{~m}$ & Seg9 & 79 & 97 & 99 & 92 & \\
\hline & $7 \mathrm{~m}$ & Seg9 & 54 & 98 & 97 & 83 & \\
\hline & $3 m$ & Seg25 & 33 & 44 & 62 & 46 & \\
\hline \multirow[t]{3}{*}{ XX06 } & $5 \mathrm{~m}$ & Seg25 & 46 & 47 & 78 & 57 & \multirow[t]{3}{*}{52} \\
\hline & $7 \mathrm{~m}$ & Seg25 & 69 & 44 & 48 & 54 & \\
\hline & $3 m$ & Seg58 & 28 & 13 & 5 & 15 & \\
\hline \multirow[t]{3}{*}{ XX01 } & $5 \mathrm{~m}$ & Seg58 & 42 & 63 & 0 & 35 & \multirow[t]{3}{*}{30} \\
\hline & $7 \mathrm{~m}$ & Seg58 & 54 & 62 & 0 & 39 & \\
\hline & Ave* & & $50 \%$ & $62 \%$ & $54 \%$ & & \\
\hline
\end{tabular}

${ }^{1.1}$ Yearly efficiency (\%) per scenario indicates each segment and corresponds to the FCW height

${ }^{1.2}$ Average efficiency (\%) indicates the average algal bloom reduction percentage for XX09, XX06 and XX01.

${ }^{1.3} \mathrm{Ave}^{*}$ means the seasonal reduction in the algal bloom percentage at sites with FCWs installed.

\section{Conclusions}

The proposed FCWs should be installed at upstream, midstream and downstream, corresponding to XX09, XX06 and XX01, respectively, at XXB in a subtropical reservoir of China to control algal blooms. A laterally averaged two-dimensional hydrodynamic and water quality model (CE-QUAL-W2) was used to simulate the hydrodynamics, temperature and chlorophyll-a concentrations using data collected in XXB from January to December 2010. Density currents are the main environmental issue that influences algal blooms year-round in XXB. These currents transport nutrients, solids and other substances from both upstream and downstream sites and those stored midstream in XXB. As a result, algal blooms occurred severely in midstream and simultaneously in the upstream and downstream flows of XXB. The maximum chlorophyll-a concentrations are $74-154 \mathrm{mg} / \mathrm{m}^{3}$ according to the scenario with no FCWs at XX09, XX06 and XX01. FCWs lead to enhanced mixing in the interior of the water body, resulting in the formation of an oscillation in the boundary layer. The XXB metalimnion layer is very thin due to the effect of FCW algal bloom intrusion, which is propagated from the epilimnion to hypolimnion layers by boundary mixing. The performance of the FCWs suggests that the overall chlorophyll-a concentrations are markedly reduced by between $30-85 \%$ as a function of the FCW height and location. The seasonal algal bloom rate was reduced by more than $62 \%, 54 \%$ and $50 \%$ in the summer, autumn and spring, respectively. FCWs with heights of $3 \mathrm{~m}, 5 \mathrm{~m}$ and 7 $\mathrm{m}$ reduced algal blooms by up to $99 \%$ at XX09 during March 26-28, April 24-27, July 18-26, August 5-20 and 23-28 and September 3-8 and 12-16, respectively. Density currents enter from upstream and downstream over the surface, middle and bottom as overflows, interflows and underflows, respectively. These density currents are interrupted by the FCWs. The performances of the $5 \mathrm{~m}, 7$ $\mathrm{m}$, and $3 \mathrm{~m}$ FCWs were more than $61 \%, 59 \%$ and $47 \%$, respectively. The FCWs with a $3 \mathrm{~m}$ height were less effective than those with $5 \mathrm{~m}$ and $7 \mathrm{~m}$ heights at midstream and downstream. The interflow decreased as the height of the FCWs increased, which allowed the algal blooms to penetrate much deeper. FCWs have become a widely accepted method for controlling algal blooms in lakes and reservoirs.

\section{Acknowledgments}

This research was supported financially by the National Key R\&D Program of China (Grant No. 2016YFC0401702), National Natural Science Foundation of China (Grant Nos. 91647207, 51709096) and China Scholarship Council (CSC) (File No. 2014DFHC97). The authors are grateful to all of the members of the Hubei Key Laboratory of Ecological Restoration of River-lakes and Algal Utilization, Wuhan, China and College of Hydraulic \& Environmental Engineering, China Three Gorges University, Yichang, 443002, Hubei, China for participating in the field monitoring.

\section{References}

[1] Ma, J., et al., Modeling density currents in a typical tributary of the Three Gorges Reservoir, China. Ecological Modelling, 2015. 296(Supplement C): p. 113-125.

[2] Yang, Z., et al., Influence of the impounding process of the Three Gorges Reservoir up to water level $172.5 \mathrm{~m}$ on water eutrophication in the Xiangxi Bay. Science China Technological Sciences, 2010. 53(4): p. 1114-1125.

[3] Yang Z J, L.D.F., Ji D B, , Influence of the impounding process of the Three Gorges Reservoir up to water level $172.5 \mathrm{~m}$ on water eutrophication in the Xiangxi Bay. Science China Technological Sciences, 2010. 53: p. 1114-1125.

[4] Ji, D., et al., Impacts of water level rise on algal bloom prevention in the tributary of Three Gorges Reservoir, China. Ecological Engineering, 2017. 98(Supplement C): p. 70-81.

[5] Ashida, K. and S. Egashira, Basic study on turbidity currents. Vol. 1975. 1975. 37-50.

[6] Benjamin, T.B., Gravity currents and related phenomena. Journal of Fluid Mechanics, 1968. 31( 2 ): p. 209-248.

[7] Kao, T.W., Density Currents and Their Applications Journal of the Hydraulics Division, 1977. 103 (5): p. 543-555.

[8] R. L. Doneker; J. D. Nash; and G. H. Jirka, Pollutant Transport and Mixing Zone Simulation of Sediment Density Currents. Journal of Hydraulic Engineering 2004. 130(4): p. 349-359.

[9] Stefan, V.A.G.H.J.R.A.D.M.C.J.a.H.G., Density Currents Entering Lakes and Reservoirs. Journal of Hydraulic Engineering, 1992 118(11).

[10] Yang, Z., et al., An eco-environmental friendly operation: An effective method to mitigate the harmful blooms in the tributary bays of Three Gorges Reservoir. Science China Technological Sciences, 2009. 56(6): p. 1458-1470.

[11] Ji, D., et al., Impacts of water level rise on algal bloom prevention in the tributary of Three Gorges Reservoir, China. Ecological Engineering, 2017. 98: p. 70-81. 
[12] Zhang, Y., et al., Effects of intrusions from Three Gorges Reservoir on nutrient supply to Xiangxi Bay. Vol. 33. 2012. 2621-7.

[13] Asaeda, T., et al., A new technique for controlling algal blooms in the withdrawal zone of reservoirs using vertical curtains. Ecological Engineering, 1996. 7(2): p. 95-104.

[14] Priyantha, D.G.N., et al., Modelling effects of curtain method on algal blooming in reservoirs. Ecological Modelling, 1997. 98(2): p. 89-104.

[15] H. S. Lee, S.W.C., J. K. Choi \& B. H. Min, Feasibility of curtain weir installation for water quality management in Daecheong Reservoir. Desalination and Water Treatment 2010. 19: p. 164-172.

[16] Se-Woong Chung, H.L.a.Y.J., The effect of hydrodynamic flow regimes on the algal bloom in a monomictic reservoir. Water Science \& Technology 2008. 58(6): p. 1291-8.

[17] Asaeda, T., et al., Control of algal blooms in reservoirs with a curtain: a numerical analysis. Ecological Engineering, 2001. 16(3): p. 395-404.

[18] Chung, S.W., H. Lee, and Y. Jung, The effect of hydrodynamic flow regimes on the algal bloom in a monomictic reservoir. Water Sci Technol, 2008. 58(6): p. 1291-8.

[19] D.G. Nimal Priyantha, T.A., Satoki Saitoh, Kohichi Gotoh, Modelling effects of curtain method on algal blooming in reservoirs. Ecological Modelling 1997. 98 p. 89-104.

[20] Wells, S., Wells, V., Berger, C., Impact of Phosphorus Loading from the Watershed on Water Quality Dynamics in Lake Tenkiller. ASCE, 2012: p. 888-899.

[21] Berger, C.J., Wells, S.A.,, Modeling the effects of macrophytes on hydrody- namics. J. Environ. Eng., 2008. 134 (9): p. 778-788.

[22] D.G. Nimal Priyantha, T.A., Graeme C. Hocking, Satoki Saitoh, Kohichi Gotoh, Yasushi Iseri, Application of a two dimensional model to predict the effects of the curtain method on algal blooming in reservoirs. Annual Journal of Hydraulic Engineering, 1997. 41: p. 415-420.
[23] Sverdrup, H.U., On conditions for the vernal blooming of phytoplankton. ICES Journal of Marine Science, 1953. 18(3): p. 287-295.

[24] Akiyama Juichiro, J.A.K., Yamasaki Tsutomu, Flow Characteristics of Surface Currents and Mixing by Curtains. Doboku Gakkai Ronbunshuu 2002. B 46: p. 1025-1030.

[25] Akiyama, J., and Stefan, H. G., Theory of Plunging Flow into a Reservoir. ASCE, 1984. 110(4): p. 484-499.

[26] Imteaz, M.A. and T. Asaeda, Artificial mixing of lake water by bubble plume and effects of bubbling operations on algal bloom. Water Research, 2000. 34(6): p. 1919-1929.

[27] Chung, S.W.L., H. Jung, Y., The effect of hydrodynamic flow regimes on the algal bloom in a monomictic reservoir. Water Sci Technol, 2008. 58(6): p. 1291-8.

[28] Waldrop, W.R. and R.C. Farmer, A computer simulation of density currents in a flowing stream. 2018.

[29] H. W. Lee, J. and V. Chu, Density Stratification. 2003. 135-177.

[30] Yi, Z., Liu, D., Yang, Z., Ma, J., Ji, D., Water temperature structure and impact of which on the bloom in spring in Xiangxi Bay at Three Gorges Reservoir. J. Hydroecol., 2009. 2(5): p. $1674-3075$.

[31] T. Asaeda, H.S.P., D.G. Nimal Priyantha, J. Manatunge, G.C. Hocking, Control of algal blooms in reservoirs with a curtain a numerical analysis. Ecological Engineering 2001. 16: p. 395-404.

[32] Connell, J.H.a.R.O.S., Mechanisms of succession in natural communities and their role in community stability and organization. The American Naturalist 1977. 111(982): p. 1119-1144.

[33] Reynolds, C.S., The intermediate disturbance hypothesis and its applicability to planktonic communities: Comments on the view of Padisak and Wilson. New Zealand Journal of Ecology 1995. 19(2)

[34] Zhao, Y.J., et al., Response of current, temperature, and algae growth to thermal discharge in tidal environment. Ecological Modelling, 2015. 318: p. 283-292.

C The Author(s) 2019. This article is an open access article distributed under the terms and conditions of the Creative Commons Attribution (CC BY) license (http://creativecommons.org/licenses/by/4.0/). 